\title{
Deficiência Mental e Família: Implicações para o Desenvolvimento da Criança ${ }^{1}$
}

\author{
Nara Liana Pereira Silva ${ }^{2}$ \\ Maria Auxiliadora Dessen \\ Universidade de Brasília
}

\begin{abstract}
RESUMO - O conceito de deficiência mental possui uma história que esteve sempre muito próxima das concepções sócioeconômicas e de homem vigentes em uma determinada sociedade. Neste artigo, apresentamos algumas questões para reflexão relativas à concepção de deficiência mental, à importância do ambiente social para o desenvolvimento da criança com deficiência mental e à dinâmica e funcionamento de famílias com crianças deficientes. A compreensão desses três aspectos e de suas inter-relações constitui a base para a promoção da saúde psicológica e o bem-estar destas crianças e de suas famílias. Concluímos que há necessidade de implementar projetos de pesquisa que focalizem a dinâmica e o funcionamento familiar, adotando conceitos apropriados de deficiência mental e de família.
\end{abstract}

Palavras-chave: deficiência mental; família; desenvolvimento infantil; relações familiares.

\section{Mental Retardation and Family: Implications for Child Development}

\begin{abstract}
The history of the concept of mental retardation has been associated with socio-economic and man conceptions from a specific society. In this article, we present some reflections related to the conception of mental retardation and the importance of social environment for the development of handicapped children, as well as the dynamic and functioning of families with mentally retarded children. The understanding of these three aspects and their connections with each other are the base to promote the psychological health and well-being of these children and their families. We conclude that it is necessary to implement research projects on family dynamics adopting appropriate concepts of mental retardation and family.
\end{abstract}

Key words: mental retardation; family; child development; family relationships.

No primeiro tópico deste artigo, abordamos questões relativas à conceituação e caracterização da deficiência mental (DM), ressaltando o conceito adotado no Brasil pelo Ministério da Educação. Em seguida, discutimos a importância do ambiente e da cultura para o desenvolvimento da criança deficiente mental e tecemos algumas considerações a respeito da importância da família nesse processo. Finalmente, apresentamos os resultados de algumas pesquisas sobre interações e relações sociais de crianças DM realizadas no contexto familiar.

\section{Deficiência Mental: Conceituação e Caracterização}

É importante conhecer as idéias que norteiam a concepção acerca da deficiência mental, em cada período histórico, para que possamos compreender melhor o lugar da criança DM na sociedade contemporânea. Para isso, recorremos a dois autores, cujas idéias resumimos a seguir. $\mathrm{O}$ primeiro

1 Este artigo é uma versão modificada da introdução da Dissertação de Mestrado da primeira autora, implementada com o apoio do CNPq.

2 Endereço: Universidade de Brasília-UnB, Instituto de Psicologia/Laboratório de Desenvolvimento Familiar. Campus Universitário, Brasília-DF, CEP: 70910-900. Fone: (61) 307-2625 ramal 417. E-mail: liana@unb.br deles é Isaías Pessoti (1984), que faz uma revisão a respeito da deficiência mental destacando as concepções, em cada período histórico, que influenciaram as atitudes da sociedade em relação à deficiência. O segundo autor, Maria Salete Aranha $(1991,1995)$, reporta à história para tratar da integração social do deficiente aliada à concepção de deficiência.

Durante a antigüidade, as crianças deficientes eram abandonadas ao relento (Aranha, 1995; Casarin, 1999; Pessoti, 1984; Schwartzman, 1999). Esta atitude era congruente com os ideais morais da sociedade clássica e classista da época, em que a eugenia e a perfeição do indivíduo eram extremamente valorizadas. Segundo Pessoti (1984), em Esparta, crianças portadoras de deficiências físicas ou mentais eram consideradas sub-humanas, o que legitimava sua eliminação ou abandono (p. 3). Na Idade Média, a deficiência era concebida como um fenômeno metafísico e espiritual devido à influência da Igreja; à deficiência era atribuído um caráter ou "divino" ou "demoníaco" e esta concepção, de certa forma, conduzia o modo de tratamento das pessoas deficientes. Com a influência da doutrina cristã, os deficientes começaram a ser vistos como possuindo uma alma e, portanto, eram filhos de Deus. Desta forma, não eram mais abandonados, mas, sim, acolhidos por instituições de caridade. Ao mesmo tempo em que imperava esse ideal cristão, os deficientes mentais eram considerados como produtos da 
união entre a mulher e o demônio, o que justificava a queima de ambos, mãe e criança (Schwartzman, 1999). Além dessa prática, usava-se também outras mais "amenas" como punições, torturas e diversos tipos de maus-tratos no lidar com essas pessoas (Aranha, 1995). Essa era a postura da sociedade daquela época, em que a ambivalência caridadecastigo constituia, de acordo com Pessoti $(1984$, p. 6) a marca definitiva da atitude medieval diante da deficiência mental.

No final do século XV, houve a revolução burguesa e, com ela, uma mudança na concepção de homem e de sociedade, o que proporcionou também uma mudança na concepção de deficiência. Esta passou a ter uma conotação mais direta com o sistema econômico que se propunha, sendo considerada atributo dos indivíduos não produtivos economicamente. Além disso, com o avanço da medicina, houve uma prevalência da visão organicista sobre a DM, sendo esta vista como um problema médico e não mais, apenas, como uma questão espiritual.

Nos séculos XVII e XVIII, ampliaram-se as concepções a respeito da deficiência em todas as áreas do conhecimento, favorecendo diferentes atitudes frente ao problema, isto é, da institucionalização ao ensino especial. Mas, foi somente no século XIX que se observou uma atitude de responsabilidade pública frente às necessidades do deficiente. No século $\mathrm{XX}$, houve uma multiplicação das visões a respeito do deficiente, com a prevalência de vários modelos explicativos: $\mathrm{o}$ metafísico, o médico, o educacional, o da determinação social e, mais recentemente, o sócio-construtivista ou sóciohistórico (Aranha, 1995) ${ }^{3}$. Segundo Nunes e Ferreira (1994), apesar da existência desses modelos, a deficiência mental ainda continua sendo considerada como um fenômeno que ocorre no sujeito; portanto, ele é o portador da deficiência.

A análise histórico-crítica do conceito de deficiência proposta por Aranha $(1991,1995)$ rompe com as visões tradicionais e mecanicistas. Essa autora ressalta a importância dos ideais e pressupostos que o sistema sócio-econômico (capitalista) possui na construção da deficiência, uma vez que esta é tratada como sendo sinônimo de improdutividade e desvio. No sistema capitalista, a produção é exigida igualmente para todos os indivíduos e aqueles que não conseguem atingir as expectativas dos detentores da produção são vistos como desviantes, estando a condição de deficiência incluída nesta categoria. Para essa autora, a deficiência é multideterminada por fatores que, aliados aos valores do sistema vigente na sociedade, levam à segregação e estigmatização dos indivíduos deficientes. Estes, por sua vez, são considerados incapazes e fracos, pois não se enquadram nos moldes produtivos do sistema capitalista. Portanto, a deficiência é vista como uma condição desvalorizada em nosso contexto social.

O rótulo de deficiente mental apresenta, por sua vez, uma dupla função, isto é, a de determinar como a pessoa DM vai se comportar na sociedade e, também, os padrões de conduta dos outros ao interagirem com esta pessoa (Glat, 1995).

3 Para uma caracterização de tais modelos, ver Nunes e Ferreira (1994).
Esta idéia coloca em evidência a questão de que a deficiência é construída pelo contexto social em que a pessoa vive. Segundo Omote (1995), o deficiente mental é uma pessoa que possui algumas limitações em suas capacidades e desempenhos; porém, há outras pessoas em nossa sociedade que também são limitadas e que não são consideradas deficientes. Esse autor afirma que:

... o nome 'deficiente' refere-se a um status adquirido por estas pessoas. Daí, temos preferido utilizar o termo 'pessoa deficiente' a utilizar o termo 'pessoa portadora de deficiência'. Nesse modo de encarar a deficiência, uma variável crítica é a audiência, porque é ela que, em última instância, vai determinar se uma pessoa é deficiente ou não. (p. 57)

Atualmente, utiliza-se o termo "necessidades especiais" ou "necessidades educativas especiais", incluindo todas as crianças avaliadas como apresentando algum tipo de necessidade educativa especial; porém, este conceito, apesar de muito abrangente, perde na precisão e pode estar significando a incorporação de um grande número de crianças, sobre as quais temos grandes dúvidas se teriam, efetivamente, algum tipo de necessidade especial (Bueno, 1997, p. 41).

Outra noção construída socialmente e que merece ser destacada aqui, por estar impregnada na própria noção de deficiência mental, refere-se à posição de desviante. Para Omote (1995) e Martins (1996), a concepção de desvio tem uma relação direta com as práticas coletivas no trato com as pessoas deficientes. Segundo Glat (1995), a rejeição da sociedade às pessoas deficientes mentais reflete a própria fragilidade social, pois tudo que é diferente e anormal chama atenção e pode causar variadas reações. Para Crochík (1997), a "diferença" é parte inerente ao conceito de deficiência e traz em si mesmo a possibilidade do preconceito, uma vez que este caracteriza-se pela aversão ao diferente. Contudo, essa diferença poderia não traduzir esta forma de preconceito se ela (a diferença) fosse reconhecida como fazendo parte da essência humana.

Para Biklen e Duchan (1994), os comportamentos julgados como desviantes advêm de uma concepção de DM pautada pelo modelo médico, o qual classifica os indivíduos em categorias diagnósticas baseadas em seus sintomas e na estrutura psicológica que presume que o comportamento reflete habilidades fixas (p. 173). Essa noção de desvio é congruente com os pressupostos de normalidade que são adotados como comparativos à deficiência mental. Esses autores fazem uma crítica a essa visão normativa de DM, em que as pessoas não deficientes mentais ("normais") são consideradas como parâmetro de comparação e diagnóstico da deficiência mental.

Alguns estudos destacam o caráter orgânico como causa da DM; dentre eles os trabalhos de Burack, Hodapp e Zigler (1988) e de Simonoff, Bolton e Rutter (1996). O primeiro deles enfatiza a existência de dois grupos distintos de indivíduos deficientes mentais: (a) aqueles que possuem uma etiologia orgânica conhecida e (b) aqueles cuja deficiência se deve a fatores culturais e familiares. Já Simonoff e seus colaboradores apontam para a existência de diferentes clas- 
ses de desordens genéticas que causam a DM: a síndrome de Down, a síndrome do $\mathrm{X}$ frágil, as anomalias do sexo cromossômico, as síndromes Prader-Willi e Angelman e, também, a fenilcetonúria. Apesar da existência de diversas causas, grande parte dos registros de deficiência mental não possui uma causa conhecida (Kovács, 1992). Mesmo assim, o fator orgânico ainda predomina em muitas concepções de deficiência mental, prevalecendo, nos diversos espaços institucionais, as visões clínica e patológica da DM como enfoque central no lidar com as pessoas deficientes mentais.

Diante desse contexto, o Ministério da Educação do Brasil (MEC) adotou um enfoque multidimensional para a caracterização da DM, inspirado no modelo proposto pela Associação Americana de Deficiência Mental (AAMR), incluindo a função intelectual e as habilidades adaptativas, a função psicológico-emocional, as funções física e etiológica e o contexto ambiental (MEC, 1995a). Este modelo enfatiza a funcionalidade do sujeito e o aspecto orgânico da deficiência, o que não deixa de estar coerente com as concepções que prevalecem na nossa sociedade, as quais refletem os valores estabelecidos pelo sistema vigente, conforme ressaltado por Aranha (1991, 1995).

Assim, observamos que ainda há questões que precisam ser aprofundadas com relação ao conceito de DM. Apesar dos esforços de alguns autores, o discurso da maior parte dos órgãos públicos e dos programas de formação de pessoal mostra que a DM continua sendo considerada como estando dentro do indivíduo, descontextualizada e sem nexo social (Nunes \& Ferreira, 1994), quando, na verdade, este conceito deveria englobar o contexto sócio-econômico e político de nossa época, bem como as influências culturais que estão presentes na construção deste sujeito concreto. Neste sentido, é importante compreendermos qual o tipo de relação que a criança estabelece com o seu ambiente, em cada momento de seu desenvolvimento.

\section{A Importância do Ambiente e da Cultura para o Desenvolvimento da Criança com Deficiência Mental}

Uma das características distintivas dos seres humanos em relação a outros animais é a sua capacidade de habitar e desenvolver-se em um ambiente organizado culturalmente através de suas crenças, valores e padrões. É nesse ambiente que a criança se desenvolve e adquire suas habilidades e é, também, nesse meio social que se dá a construção da deficiência mental.

\section{O ambiente e o desenvolvimento infantil}

O papel que o ambiente representa no desenvolvimento infantil varia muito, dependendo da idade da criança. À medida que esta se desenvolve, seu ambiente também muda e, conseqüentemente, a sua forma de relação com este meio se altera. Assim, para o recém-nascido, o mundo que se relaciona imediatamente com ele é um mundo limitado e ligado aos fenômenos conectados ao seu corpo e aos objetos que o rodeiam. Depois, gradualmente, este mundo começa a se ampliar, embora ainda se trate de um mundo restrito que inclui a sala, o quintal próximo e a rua onde ele vive. Quando o bebê começa a andar, seu ambiente expande e novos relacionamentos são formados entre a criança e as pessoas que a circundam (Vygotsky, 1994, p. 339). Portanto, o ambiente é mutável e dinâmico, não devendo ser encarado como uma entidade estática e periférica em relação ao desenvolvimento humano. É dentro desse contexto que inserimos a nossa criança com deficiência mental, a qual apresenta limitações em suas capacidades, porém sem estar imune às transformações de seu ambiente.

$\mathrm{O}$ ambiente possui as fontes necessárias para o desenvolvimento da criança, bem como apresenta traços humanos específicos que são característicos do desenvolvimento social e histórico da humanidade (Vygotsky, 1994). Na concepção desse autor, o ambiente já possui uma forma apropriada, a qual deve estar em relação com a forma rudimentar da criança, para que o desenvolvimento possa ocorrer sem falhas. Se uma forma ideal apropriada não é encontrada no ambiente, se não há uma interação da criança com esta forma, então, surge a possibilidade de um fracasso em algum aspecto do desenvolvimento infantil.

A relação entre o ambiente e o desenvolvimento humano é também enfatizada por Bronfenbrenner (1996), para quem a pessoa é concebida como um todo funcional onde os diversos processos psicológicos - cognitivo, afetivo, emocional, motivacional e social - relacionam-se de forma coordenada um com o outro. Para ele, existem conexões sociais entre os vários ambientes, incluindo a participação conjunta, a comunicação e a existência de informações a respeito do outro, em cada ambiente. Isto permite que a pessoa no microsistema familiar, por exemplo, possa ser influenciada por todos os outros sistemas e se desenvolva nessa interação.

Os genitores e sua criança têm acesso ao ambiente, sobretudo, através das crenças e das normas construídas pela cultura, as quais medeiam a relação entre eles. Existem diferentes culturas e cada qual caracteriza-se por seu código de valores e crenças específicas. O modo como a criança pensa e usa uma habilidade intelectual depende dos modelos culturais de competência, enquanto o que ela sente e como atua em direção às pessoas com as quais possui vínculo depende dos modelos culturais de relações interpessoais (LeVine, 1989, p. 57). Nesse sentido, não há diferenciação entre crianças DM e não DM, pois ambas estão inseridas nesse processo de transmissão cultural, encontrando-se em contínua interação com o meio social.

A diversidade cultural propicia a construção de diferentes modos de criação e educação de crianças. Porém, os genitores possuem, também, objetivos universais em relação aos filhos, que independem da cultura em que estão inseridos, tais como a saúde da criança, a sobrevivência física e sua satisfação pessoal e auto-realização (Sinha, 1995). No entanto, o nascimento de uma criança DM pode provocar várias reações e sentimentos dentro da família, bem como mudar a estrutura familiar estabelecida antes de seu nascimento. A literatura (Brito \& Dessen, 1999; Casarin, 1999; 
Cuskelly \& Dadds, 1992; Leary \& Verth, 1995; Sloper, Knussen, Turner \& Cunningham, 1991) tem demonstrado uma grande variedade de reações e sentimentos vivenciados pela família, sugerindo que cada uma apresenta recursos diferentes para enfrentar as dificuldades com suas crianças deficientes.

\section{A família como contexto de desenvolvimento para a criança DM}

A família constitui o primeiro universo de relações sociais da criança, podendo proporcionar-lhe um ambiente de crescimento e desenvolvimento, especialmente em se tratando das crianças com deficiência mental, as quais requerem atenção e cuidados específicos. A influência da família no desenvolvimento de suas crianças se dá, primordialmente, através das relações estabelecidas por meio de uma via fundamental: a comunicação, tanto verbal como não verbal. Como afirmam Rey e Martinez (1989), a família representa, talvez, a forma de relação mais complexa e de ação mais profunda sobre a personalidade humana, dada a enorme carga emocional das relações entre seus membros (p. 143).

A gama de interações e relações desenvolvidas entre os membros familiares mostra que o desenvolvimento do indivíduo não pode ser isolado do desenvolvimento da família (Dessen \& Lewis, 1998). A família constitui um grupo com dinâmicas de relação muito diversificadas, cujo funcionamento muda em decorrência de qualquer alteração que venha a ocorrer em um de seus membros ou no grupo como um todo. Para Kreppner (1992), a rede de relações da família possui características específicas de unicidade e complexidade, constituindo um contexto em desenvolvimento. Segundo este autor, a complexidade das relações familiares pode, também, ser entendida por meio da perspectiva da família como um ambiente não compartilhado, onde as relações desenvolvidas entre seus membros geram experiências diferenciadas para cada um. Portanto, cada membro da família vivencia, de maneira particular, a chegada de uma criança com deficiência.

O impacto sentido pela família com a chegada de uma criança com algum tipo de deficiência é intenso. Segundo Brito e Dessen (1999), esse momento é traumático, podendo causar uma forte desestruturação na estabilidade familiar. O momento inicial é sentido como o mais difícil para a família (Petean, 1995), a qual tem que buscar a sua reorganização interna (Taveira, 1995) que, por sua vez, depende de sua estrutura e funcionamento enquanto grupo e, também, de seus membros, individualmente.

A família passa, então, por um longo processo de superação até chegar à aceitação da sua criança com deficiência mental: do choque, da negação, da raiva, da revolta e da rejeição, dentre outros sentimentos, até a construção de um ambiente familiar mais preparado para incluir essa criança como um membro integrante da família. Segundo Casarin (1999), a reorganização familiar fica mais fácil quando há apoio mútuo entre o casal. Nesse caso, o ambiente familiar pode contribuir para o desenvolvimento e crescimento da criança DM. Contudo, o ambiente pode também dificultar essa reorganização interna da família, principalmente porque o nascimento de uma criança, por si só, já acarreta alterações que constituem um desafio para todos os membros familiares (Dessen, 1997; Kreppner, 1989, 1992).

As famílias restabelecem o seu equilíbrio de maneira variada, dependendo dos recursos psicológicos utilizados para tal fim. Gallimore, Coots, Weisner, Garnier e Guthrie (1996) mostram que as adaptações das famílias de crianças pré-escolares com atraso no desenvolvimento apresentam um panorama misto de continuidades e mudanças em seus padrões de interação até a segunda infância da criança. De acordo com estes autores, em todas as idades, a adaptação da família está relacionada às características da criança, as quais exercem um impacto direto na rotina diária dos membros familiares.

São muitas as variáveis que afetam o desenvolvimento da criança. Para Zamberlan e Biasoli-Alves (1996), tanto fatores macrosistêmicos - renda familiar, grau de instrução dos pais e profissão, como microsistêmicos - qualidade das interações e relações entre os membros familiares e pessoas próximas, particularmente no que tange às práticas psicossociais de cuidados implementadas nesses contextos, associam-se na promoção de um desenvolvimento adequado e saudável da criança. Aprofundar o conhecimento sobre o funcionamento de famílias de crianças deficientes mentais constitui um caminho promissor para a compreensão do desenvolvimento destas crianças e de sua adaptação ao meio. Assim, destacamos, a seguir, algumas pesquisas que descrevem aspectos das relações dessas crianças com suas famílias.

\section{Pesquisas Sobre Crianças DM no Contexto Familiar: Um Panorama Geral}

Neste tópico, apresentamos os resultados de algumas pesquisas conduzidas com crianças com deficiência mental e suas famílias. Primeiramente, focalizamos estudos referentes aos sentimentos e estado emocional dos genitores em relação à sua criança DM. Em seguida, enfatizamos alguns trabalhos que descrevem os efeitos dessas crianças no contexto familiar, incluindo os problemas de comportamento apresentados por elas. Finalmente, tecemos algumas considerações sobre a importância das interações e relações das crianças DM com seus genitores.

\section{Sentimentos, estresse e expectativas de pais e mães de crianças DM}

Os sentimentos dos genitores em relação à sua criança com deficiência constituem fatores preponderantes para a adaptação e o bem-estar da família. Segundo Leary e Verth (1995), as mães de seu estudo relataram mágoa e sofrimento em relação à difícil situação de suas crianças deficientes mentais. A culpa foi também relatada por essas mães, porém, com uma frequiência menor. No estudo de Ali, Al-Shatti, Khaleque, Rahman, Ali e Ahmed (1994), esse sentimento foi relatado tanto pelos pais como pelas mães, os quais se 
responsabilizavam pela deficiência mental de suas crianças. Em geral, as pressões vindas do meio social geram sentimentos desagradáveis, levando os genitores a limitarem as atividades culturais de seus filhos deficientes, bem como os contatos com amigos, parentes e vizinhos (Ali \& cols., 1994; Brito \& Dessen, 1999). Ali e seus colaboradores identificaram vários fatores que poderiam constituir uma sobrecarga para os genitores, como: (a) o tempo - os genitores gastam muito tempo no cuidado e atenção às suas crianças deficientes, reduzindo seus contatos sociais e culturais; (b) os recursos financeiros - os genitores arcam financeiramente com a maioria dos atendimentos à sua criança; (c) os limites sociais e psicológicos - as atitudes da sociedade em relação às pessoas com deficiência mental, geralmente, não são positivas.

Alguns estudos demonstram níveis altos de estresse em genitores de crianças DM, com as mães apresentando níveis superiores aos dos pais (Dyson, 1997; Hornby, 1995; Lamb \& Billings, 1997; Sloper \& cols., 1991). Devido ao fato de as mães ficarem, geralmente, responsáveis pela maior parte dos cuidados adicionais dispensados à criança DM, elas tendem a relatar níveis mais altos de estresse. Em contraposição os pais relatam, freqüentemente, menor satisfação com a vida familiar, como um resultado de demandas extras de acomodação à criança deficiente. Os resultados de Hornby revelam que o estresse experienciado pelos pais de crianças com síndrome de Down está relacionado ao status empregatício, à satisfação marital e a variáveis de personalidade, apresentando uma relação inversa com o nível educacional e a condição financeira. Já os dados de Dyson mostram que o estresse parental está relacionado à própria avaliação do genitor e do seu cônjuge a respeito do funcionamento da família, em aspectos como educação, promoção do crescimento pessoal e habilidade para manter o sistema familiar. Portanto, tanto variáveis internas como externas colaboram para aumentar o estresse vivenciado pelos genitores e exercem, direta ou indiretamente, influência nas interações e relações familiares.

Nem sempre os genitores adotam uma forma adequada para lidar com as situações advindas de se ter uma criança deficiente na família, mostrando-se ora condescendentes, ora impacientes e, às vezes, revelando atitudes de depreciação em relação ao próprio filho (Petean, 1995). As estratégias de enfrentamento adotadas por eles são diversificadas. As mais utilizadas, segundo Rodrigue, Morgan e Geffken (1992), são a procura por informações sobre a deficiência e as fantasias de satisfação de desejos, de como eles poderiam lidar com as situações difíceis e de como seria o progresso no desenvolvimento de sua criança. Lamb e Billings (1997) afirmam que os pais freqüentemente têm expectativas mais altas em relação aos filhos do que às filhas; eles ficam particularmente desapontados quando um filho é diagnosticado como tendo retardo mental (p. 181). Porém, Hornby (1995) não encontrou diferença significativa com relação à adaptação dos pais de meninos e meninas com síndrome de Down. Esses dados mostram a necessidade de pesquisas sobre os aspectos psico-emocionais dos genitores de crianças DM.

\section{Como a família percebe sua criança DM?}

Considerando a perspectiva do funcionamento da família, Carr (1988) efetuou um estudo longitudinal com uma amostra de 41 crianças com síndrome de Down e 30 não deficientes, que foram acompanhadas em sete ocasiões, desde a sexta semana de vida até os quatro anos de idade e, novamente, aos 11 e aos 21 anos. Foi enviado, também, por correio, um questionário às famílias das crianças com síndrome de Down quando elas completaram 16 anos de idade. Este estudo visou investigar aspectos do desenvolvimento cognitivo e acadêmico da criança, além dos aspectos relativos ao funcionamento da família. A respeito deste último, foram analisadas duas categorias gerais: (a) o manejo prático da criança, englobando as habilidades para a realização de atividades diárias (tomar banho, enxugar-se, vestir-se etc.), o manejo dos comportamentos da criança e o conseqüente monitoramento por parte dos pais; (b) os efeitos da criança sobre a família como um todo, particularmente sobre os irmãos e o casamento dos pais.

Os resultados mostram que as mães consideram que, aos 21 anos, os filhos são mais fáceis de manejar, sendo o domínio das habilidades apropriadas para a realização das atividades diárias visto como significativo, tanto para a família como para o deficiente em questão. Nenhuma desvantagem advinda do fato de se ter uma criança com síndrome de Down na família foi constatada, principalmente em relação aos efeitos sobre os irmãos. No entanto, esses dados são contraditórios aos encontrados por Turnbull e Ruef (1996), em uma amostra de famílias que possuía uma criança com deficiência mental. Segundo esses autores, seus respondentes afirmaram haver problemas específicos de relacionamento entre irmãos e, também, em relação à família extensa, principalmente nos casos de crianças com deficiência mental que apresentavam problemas de comportamento. Os genitores dessas crianças relataram que permaneciam 24 horas por dia "a serviço" da criança: em supervisão, intervenção e tentativas para prevenir os seus problemas de comportamento.

No estudo de Leary e Verth (1995), 45\% das mães de crianças com deficiência mental relataram que seus outros filhos aceitavam inteiramente a criança com deficiência, enquanto $27 \%$ percebiam problemas de comportamento, que foram atribuídos à presença da criança deficiente. Já Cuskelly e Dadds (1992) apontaram a depressão como um problema de comportamento freqüentemente observado nos irmãos das crianças com síndrome de Down e Bagenholm e Gillberg (1991), por sua vez, descreveram as percepções dos irmãos de crianças DM, autistas e crianças não deficientes, na perspectiva dos próprios irmãos. Os resultados mostram que todos eles foram positivos em suas expressões ao se referirem a seus irmãos com deficiência, embora $65 \%$ dos irmãos do grupo de DM não soubessem explicar o porquê de seu irmão ser diferente dos outros. Não foram relatados problemas de solidão entre os irmãos das crianças DM, embora no grupo de autistas, $35 \%$ tenham relatado sentir solidão. Os dados também revelam que os irmãos do grupo de crianças DM brincavam mais que os outros grupos de irmãos. 
Os estudos realizados com o pai de crianças DM são escassos (Herbert \& Carpenter, 1994; Hornby, 1995; Rodrigue $\&$ cols., 1992). A maioria deles procura enfatizar a percepção do pai a respeito de sua criança; no entanto, há outros estudos cuja ênfase é dada ao engajamento do pai na vida familiar. $\mathrm{O}$ estudo de Rodrigue e seus colaboradores, por exemplo, descreve a adaptação psicossocial de pais de crianças com autismo, síndrome de Down e com desenvolvimento normal, evidenciando maiores desequilíbrios no planejamento familiar nas famílias de crianças com autismo e síndrome de Down e, também, um crescente desajuste financeiro por causa dessas crianças. Esses pais revelaram, ainda, níveis de competência parental, satisfação marital e apoio social compatíveis àqueles relatados pelos pais de crianças com desenvolvimento normal.

Segundo Sloper e seus colaboradores (1991), para os pais de crianças deficientes, a qualidade do relacionamento marital está, primordialmente, relacionado à satisfação com a vida e com a família como um todo. Os pais de sua amostra sentiam-se mais satisfeitos com a paternidade, porém, apresentavam baixos níveis de satisfação financeira, sugerindo que os efeitos da criança sobre eles eram menores que os efeitos ambientais externos. Esses autores concluíram que fatores como a criança, o ambiente social e os aspectos parentais interagem, produzindo a satisfação e o estresse familiar. Contudo, para as mães, os fatores como baixa resistência e alta excitabilidade da criança estão fortemente relacionados à baixa satisfação com a vida.

Com relação aos problemas de comportamento apresentados por crianças DM, a literatura é relativamente vasta (Cuskelly \& Dadds, 1992; Leary \& Verth, 1995; Lemanek, Stone \& Fishel, 1993; Turnbull \& Ruef, 1996). Os problemas de comportamento relatados são, em geral, diversificados e dependem do tipo de deficiência e do grau de comprometimento da criança. Por exemplo, as crianças com síndrome de Down, no estudo de Cuskelly e Dadds, apresentaram mais problemas de comportamento que seus irmãos, destacando-se os problemas de atenção e imaturidade. Já Turnbull e Ruef encontraram crianças deficientes mentais com problemas comportamentais mais graves, tais como agressão a outros, comportamentos de destruição e de auto lesão, entre outros.

Para Cuskelly e Dadds (1992), há divergências entre as percepções da mãe, do pai e da professora quanto aos problemas de comportamento observados em meninas e meninos DM. Segundo as mães, meninos e meninas apresentam os mesmos tipos e intensidades de problemas; porém, para os pais, são as meninas que apresentam mais problemas, enquanto a professora sente mais dificuldades em lidar com os meninos. Para esses autores, as percepções parentais e da professora não explicam, por si só, a complexidade da questão e não devem ser consideradas determinantes na classificação do distúrbio da criança. Para compreender melhor a dinâmica e o funcionamento destas famílias e o processo de desenvolvimento de suas crianças, é preciso, sobretudo, conhecer como se desenvolvem as interações e as relações entre elas e seus genitores e irmãos.

\section{Estudos Sobre Interações da Criança DM com Seus Genitores}

As interações desenvolvidas no microsistema familiar são, provavelmente, as que trazem implicações mais profundas para o desenvolvimento infantil. Os estudos sobre interações familiares de crianças DM são escassos, especialmente no Brasil. Dada a importância do tema e a complexidade das interações e relações para o desenvolvimento das famílias de crianças DM, Dessen e Pereira-Silva (no prelo) realizaram um estudo sobre as produções científicas nacional e estrangeira a respeito de crianças pré-escolares com deficiência mental e suas famílias, confirmando a escassez de estudos nesta área, principalmente em se tratando das interações e relações dos membros familiares em ambiente natural.

A análise destas autoras (Dessen \& Pereira-Silva, no prelo) compreendeu o período de 1986 a 1999, sendo realizada uma pesquisa bibliográfica através do Psychological Abstracts e das bases de dados PsyClit e ProQuest, bem como uma consulta aos Anais da Reunião Anual de Psicologia/ SBP e às seguintes revistas brasileiras: Cadernos de Psicologia e Educação Paidéia, Psicologia: Reflexão e Crítica, Psicologia: Teoria e Pesquisa, Revista Integração e Temas em Psicologia. Além destas fontes, realizou-se também pesquisa bibliográfica através da internet, junto ao site da Universidade de São Paulo (sistema Dedalus).

Foram registradas um total de 304 produções, incluindo artigos teóricos e de pesquisas, teses, livros e capítulos de livros. A "definição de deficiência mental" foi o assunto mais enfatizado nos artigos consultados (41\%), seguido pelo tema "família e sua criança deficiente mental" $(33,7 \%)$. As "interações no contexto familiar" foram investigadas com mais frequiência $(18,7 \%)$ que as "interações em outros contextos" $(6,6 \%)$. Em se tratando do primeiro contexto, as interações entre a mãe e a criança foram mais estudadas (39\%) que outras, tais como pai-criança ou criança-irmãos. As autoras (Dessen \& Pereira-Silva, no prelo) concluíram que os artigos publicados no Brasil tratam das "interações no contexto familiar" com menor frequiência que os estrangeiros, quadro que precisa ser modificado, principalmente no que se refere à inclusão da figura do pai. Na verdade, há necessidade de implementar pesquisas envolvendo todos os membros da família, isto é, os diversos subsistemas familiares: mãe-criança, pai-criança, criança-irmão, mãe-pai-criança etc., particularmente em se tratando de famílias que possuem uma criança com algum tipo de deficiência.

Diante deste panorama geral, Pereira-Silva (2000) descreveu as interações criança-mãe, criança-pai e criança-mãepai, em situação de atividade livre, de seis famílias que possuíam uma criança com síndrome de Down, com idades variando entre dois e três anos e cinco meses. Estas crianças participavam do Programa de Estimulação Precoce oferecido pela Fundação Educacional do Distrito Federal, em Brasília. Para a coleta de dados, foram utilizados três instrumentos: questionário, entrevistas semi-estruturadas e observação direta do comportamento. As sessões de observação 
foram efetuadas nas residências das famílias, perfazendo um total de 18 sessões de observação, gravadas em videoteipe, com duração média de 9 min. e 51 seg., totalizando $171 \mathrm{~min}$. e 33 seg. de gravação. As filmagens ocorreram durante a realização de "Atividades Livres", nas situações em que estavam presentes a criança e um ou ambos os genitores.

Os dados observacionais foram analisados segundo as atividades realizadas, a estrutura de participação dos membros familiares nas atividades, a iniciativa das interações, a qualidade das interações e os comportamentos específicos emitidos pela criança em direção aos genitores e destes em direção à criança. Os genitores engajaram-se mais freqüentemente em atividades 'Lúdicas' com suas crianças, 'Brincando com objetos' e 'Conversando sobre estímulos presentes'. As atividades foram desenvolvidas, geralmente, em 'Grupo', havendo predominância da participação 'Conjunta'. O pai foi o maior responsável pelo início das interações e foi ele, também, quem mais negociou com a criança durante as mudanças de uma atividade para outra. Estas mudanças ocorreram, freqüentemente, de forma 'Direta', mais do que pela 'Dissolução do grupo'. As interações caracterizaram-se pela 'Sincronia', 'Supervisão', 'Amistosidade' e 'Liderança'. Os genitores emitiram, com mais frequiência, o comportamento de 'Solicitar/Sugerir' e as crianças responderam, predominantemente, com o comportamento de 'Rejeitar', seguido pelo de 'Obedecer'. Foram pouco freqüentes os comportamentos de 'Ordenar' e 'Solicitar/Sugerir' emitidos pelas crianças, indicando que estas respondiam mais às demandas de seus genitores do que exigiam deles. Os genitores descreveram as suas crianças como sendo birrentas, calmas ou agitadas, irritadas e como tendo facilidades de adaptação ao meio. As expectativas dos genitores em relação ao futuro de seus filhos são de que eles se tornem adultos independentes, estudem, tenham uma profissão e que possam até ter um relacionamento íntimo com uma pessoa do sexo oposto.

Os resultados sugerem que, nestas famílias, a mãe é a maior responsável pelos cuidados e pela transmissão de regras às crianças com síndrome de Down. O pai, por sua vez, desempenha um papel secundário, envolvendo-se menos com a rotina da casa, embora inicie interações com sua criança com uma freqüência similar à da mãe. Assim, a elaboração de programas preventivos, com ênfase nas interações familiares e no papel do pai, e a implementação de pesquisas incluindo todos os membros familiares contribuiriam para uma melhor compreensão do desenvolvimento das crianças com síndrome de Down e do funcionamento de suas famílias.

\section{Considerações Finais}

A compreensão dos aspectos mais amplos que cerceiam as famílias que possuem crianças DM passa por questões relacionadas aos conceitos de deficiência mental e de família e sua importância para o desenvolvimento infantil. Com relação ao conceito de deficiência mental, verificamos uma multiplicidade de concepções, as quais acabam por não delimitar com clareza o fenômeno que se pretende estudar. Sobre o conceito de família, observamos uma mudança ocor- rida ao longo dos anos, indicando que, com o desenvolvimento e mudanças nas sociedades, os estilos de família mudaram. Portanto, considerar a família como uma unidade nuclear tradicional já não satisfaz, tendo em vista as diversas variáveis que se combinam para a caracterização da família atual (Brito \& Dessen, 1999; Dessen \& Lewis, 1998; Petzold, 1996). As mudanças ocorridas e que vem ocorrendo no contexto social e histórico (Crouter \& Seery, 1994) têm acarretado modificações nos diversos padrões de relacionamento dentro do contexto familiar. Além desses aspectos, Menaghan (1994) ainda inclui os fatores econômico e ocupacional como afetando drasticamente as relações familiares, principalmente aquelas entre os genitores e a sua criança.

Dada a importância do ambiente para o desenvolvimento da criança, tanto "normal" quanto "deficiente", no que tange à organização de suas atividades de vida diária e ao processo de estimulação, torna-se fundamental compreender como o ambiente influencia o desenvolvimento das crianças, principalmente daquelas que apresentam algum tipo de deficiência. Vygotsky (1994) afirma que a influência do ambiente sobre o desenvolvimento infantil, ao lado de outros tipos de influências, também deve ser avaliada levando em consideração o grau de entendimento, a consciência e o insight do que está acontecendo no ambiente em questão ( $\mathrm{p}$. 343). Essa afirmativa traz às nossas mentes indagações importantes do tipo: a criança DM recebe menos influência do ambiente por ter menos condições cognitivas para a compreensão e consciência das situações vivenciadas? Para este autor, as crianças deficientes mentais severas, que não têm as aquisições cognitivas preservadas, acabam sendo poupadas e protegidas de situações que, para as crianças não deficientes, poderiam causar extremo sofrimento. É interessante destacar que a vivência da criança DM, em comparação à criança não DM, ocorre de forma diferenciada devido às suas limitações, mas isso não significa que os acontecimentos do ambiente não tenham um impacto sobre ela. Na verdade, ainda não há respostas prontas para as indagações que nós nos fazemos, enquanto pesquisadores.

O microsistema da família não é o único que precisa ser estudado. Há também o ambiente da escola, que constitui mais um espaço de socialização para a criança com deficiência. Em relação a isso, muito se tem discutido a respeito da inclusão da criança deficiente em ambiente coletivo, mostrando a sua importância e necessidade. Aranha (1995) afirma que, ao impedir a integração social do deficiente, há perdas tanto para a pessoa (deficiente) em desenvolvimento como para a sociedade. Com isto, todos perdemos em consciência, em comportamento e, conseqüentemente, em possibilidade de transformação (p. 70). Apesar da importância da escola, não devemos esquecer que as intervenções devem ocorrer, primeiramente, na família enquanto um grupo em desenvolvimento. Contudo, não basta somente estudar a família, é preciso focalizá-la inserida dentro de um contexto ecológico mais amplo, se quisermos, de fato, compreender a sua dinâmica e funcionamento. Em relação a este aspecto, muito ainda tem que ser feito em se tratando de famílias com crianças que apresentam algum tipo de deficiência. 
Para finalizar, é importante ressaltar a necessidade de mais orientação para as famílias de crianças DM, as quais devem ser melhor informadas sobre o tipo de deficiência e suas conseqüências para o desenvolvimento da criança, bem como dos recursos necessários para favorecê-lo. Nesse contexto, as políticas públicas têm um papel muito importante, especialmente para as famílias de baixa renda, uma vez que o gasto com profissionais e com atendimento especializado torna-se oneroso. O Ministério da Educação do Brasil (MEC) é o responsável, em nosso país, pela organização e administração do ensino especial, juntamente com a participação estadual e, às vezes, municipal (MEC, 1994). Esse atendimento é garantido por lei; contudo, ele ainda é deficitário e conta com o despreparo dos profissionais. Além disso, os currículos escolares não contemplam o ensino especial como uma disciplina necessária nos cursos de magistério e pedagogia (Martins, 1996). Mas, merece ser destacado aqui um programa de estimulação precoce, que faz parte dos diversos tipos de atendimentos planejados pelo MEC para beneficiar as crianças de zero a três anos com atraso no desenvolvimento ou com deficiências (física, mental, visual, auditiva, múltipla). Esse programa tem, em sua essência, um papel preventivo, buscando intervir nas diversas áreas do desenvolvimento infantil: motora, cognitiva, sensório-perceptiva, socioafetiva e da linguagem (MEC, 1995b). Assim, considerando a necessidade desse tipo de atendimento, entendemos ser de fundamental importância mais investimentos nessa área, atingindo mais estados e municípios brasileiros que, concomitantemente ao aumento do número de pesquisas sobre crianças DM e suas famílias, proporcionariam uma compreensão mais profunda do seu desenvolvimento.

\section{Referências}

Ali, M.R., Al-Shatti, A., Khaleque, A., Rahman, A., Ali, S.M. \& Ahmed, R.U. (1994). Parents of mentally retarded children: Personality characteristics and psychological problems. Social Behavior and Personality, 22, 41-52.

Aranha, M.S.F. (1991). A interação social e o desenvolvimento de relações interpessoais do deficiente em ambiente integrado. Tese de Doutorado, Universidade de São Paulo, São Paulo.

Aranha, M.S.F. (1995). Integração social do deficiente: análise conceitual e metodológica. Temas em Psicologia, 2, 63-70.

Bagenholm, A. \& Gillberg, C. (1991). Psychosocial effects on siblings of children with autism and mental retardation: A population-based study. Journal of Mental Deficiency Research, 35, 291-307.

Biklen, D. \& Duchan, J.F. (1994). "I am intelligent": The social construction of mental retardation. Journal of Association for Persons with Severe Handicaps, 19, 173-184.

Brito, A.M.W. \& Dessen, M.A. (1999). Crianças surdas e suas famílias: um panorama geral. Psicologia: Reflexão e Crítica, 12, 429-445.

Bronfenbrenner, U. (1996). A ecologia do desenvolvimento humano: experimentos naturais e planejados. (M.A.Veríssimo, trad.) Porto Alegre: Artes Médicas. (Trabalho originalmente publicado em 1979)
Bueno, J.G.S. (1997). Práticas institucionais e exclusão social da pessoa deficiente. Em Conselho Regional de Psicologia de São Paulo (Org.), Educação especial em debate (pp. 37-54). São Paulo: Casa do Psicólogo.

Burack, J.A., Hodapp, R.M. \& Zigler, E. (1988). Issues in the classification of mental retardation: Differentiating among organic etiologies. Journal of Child Psychology and Psychiatry, 29, 765-779.

Carr, J. (1988). Six weeks to twenty-one years old: A longitudinal study of children with Down's syndrome and their families. Journal of Child Psychology and Psychiatry, 29, 407-431.

Casarin, S. (1999). Aspectos psicológicos na síndrome de Down. Em J.S. Schwartzman (Org.), Sindrome de Down (pp. 263-285). São Paulo: Mackenzie.

Crochík, J.L. (1997). Aspectos que permitem a segregação na escola pública. Em Conselho Regional de Psicologia de São Paulo (Org.), Educação especial em debate (pp. 13-22). São Paulo: Casa do Psicólogo.

Crouter, A.C. \& Seery, B. (1994). Looking to the future: Diversity in family experience and developmental paths. Em L. L'Abate (Org.), Handbook of developmental family psychology and psychopathology (pp. 415-432). New York: John Wiley \& Sons.

Cuskelly, M. \& Dadds, M. (1992). Behavioural problems in children with Down's syndrome and their siblings. Journal of Child Psychology and Psychiatry, 33, 749-761.

Dessen, M.A. (1997). Desenvolvimento familiar: transição de um sistema triádico para poliádico. Temas em Psicologia, 3, 51-61.

Dessen, M.A. \& Lewis, C. (1998). Como estudar a família e o "pai". Cadernos de Psicologia e Educação Paidéia, 8(14/15), 105-121.

Dessen, M.A. \& Pereira-Silva, N.L. (no prelo). Análise da produção científica na área de deficiência mental e família. Cadernos de Psicologia e Educação Paidéia.

Dyson, L.L. (1997). Fathers and mothers of school-age children with developmental disabilities: Parental stress, family functioning and social support. American Journal on Mental Retardation, 102, 267-279.

Gallimore, R., Coots, J., Weisner, T., Garnier, H. \& Guthrie, D. (1996). Family responses to children with early developmental delays II: Accommodation intensity and activity in early and middle childhood. American Journal on Mental Retardation, $101,215-232$.

Glat, R. (1995). Integração dos portadores de deficiências: uma questão psicossocial. Temas em Psicologia, 2, 89-94.

Herbert, E. \& Carpenter, B. (1994). Fathers - The secondary partners: Professional perceptions and fathers' reflections. Children \& Society, 8, 31-41.

Hornby, G. (1995). Effects on fathers of children with Down syndrome. Journal of Child and Family Studies, 4, 239-255.

Kovács, M.J. (1992). Desenvolvimento e deficiência mental [Resumo]. Em Sociedade Brasileira de Psicologia (Org.), XXI Reunião Anual de Psicologia (pp. 368-372). Ribeirão Preto: SBP.

Kreppner, K. (1989). The interplay between individual and family development: Some results from a 7 - year longitudinal study. Em M.A. Luszcz \& T. Nettelbeck (Orgs.), Psychological development: Perspectives across the life-span (pp. 25-36). NorthHolland: Elsevier Science Publishers. 
Kreppner, K. (1992). Development in a developing context: Rethinking the family's role for children's development. Em L.T. Winegar \& J. Valsiner (Orgs.), Children's development within social context (pp.161-179). Hillsdale: Lawrence Erlbaum.

Lamb, M.E. \& Billings, L.A.L. (1997). Fathers of children with special needs. Em M.E. Lamb (Org.), The role of the father in child development (pp. 179-190). New York: John Wiley.

Leary, P.M. \& Verth, F. (1995). The effects of a mentally retarded child on family functioning in a third world community. Early Child Development and Care, 109, 83-88.

Lemanek, K.L., Stone, W.L. \& Fishel, P.T. (1993). Parent-child interactions in handicapped preschoolers: The relation between parent behaviors and compliance. Journal of Clinical Child Psychology, 22, 68-77.

LeVine, R.A. (1989). Cultural environments in child development. Em W. Damon (Org.), Child development today and tomorrow (pp. 52-68). San Francisco, CA: Jossey-Bass.

Martins, L.A.R. (1996). Educação integrada do portador de deficiência mental. Revista Integração, 16, 27-32.

MEC- Ministério da Educação do Brasil (1994). Educação especial no Brasil. Brasília, DF: Autor.

MEC- Ministério da Educação do Brasil (1995a). Subsídios para organização e funcionamento de serviços de educação especial: área de deficiência mental. Brasília, DF: Autor.

MEC- Ministério da Educação do Brasil (1995b). Diretrizes sobre estimulação precoce: o portador de necessidades educativas especiais. Brasília, DF: Autor.

Menaghan, E.G. (1994). Linking societies, families and individuals over time: The challenge of a developmental psychology of families. Em L. L'Abate (Org.), Handbook of developmental family psychology and psychopathology (pp. 375-391). New York: John Wiley \& Sons.

Nunes, L.R.O.P. \& Ferreira, J.R. (1994). Deficiência mental: o que as pesquisas brasileiras têm revelado. Em E.M.L.S. de Alencar (Org.), Tendências e desafios da educação especial (pp. 5081). Brasília: MEC/SEESP.

Omote, S. (1995). A integração do deficiente: um pseudo-problema científico. Temas em Psicologia, 2, 55-62.

Pereira-Silva, N.L. (2000). Crianças pré-escolares com síndrome de Down e suas interações familiares. Dissertação de Mestrado, Universidade de Brasília, Brasília-DF.

Pessoti, I. (1984). Deficiência mental: da superstição à ciência. São Paulo: EDUSP.

Petean, E.B.L. (1995). Avaliação qualitativa dos aspectos psicológicos do aconselhamento genético através do estudo prospectivo do atendimento das famílias. Tese de Doutorado, Faculdade de Ciências Médicas da UNICAMP, Campinas.

Petzold, M. (1996). The psychological definition of "the family". Em M. Cusinato (Org.), Research on family: Resources and needs across the world (pp. 25-44). Milão: LED - Edicioni Universitarie.

Rey, F.G. \& Martinez, A.M. (1989). La personalidad: su educación y desarrollo. La Habana: Editorial Pueblo y Educación.

Rodrigue, J.R., Morgan, S.B. \& Geffken, G.R. (1992). Psychosocial adaptation of fathers of children with autism, Down syndrome and normal development. Journal of Autism and Development Disorders, 22, 249-263.
Schwartzman, J.S. (1999). Histórico. Em J.S. Schwartzman (Org.), Sindrome de Down (pp. 3-15). São Paulo: Mackenzie.

Simonoff, E., Bolton, P. \& Rutter, M. (1996). Mental retardation: Genetic findings, clinical implications and research. Journal of Child Psychology and Psychiatry, 37, 259-280.

Sinha, S.R. (1995). Childrearing practices relevant for the growth of dependency and competence in children. Em J. Valsiner (Org.), Child development within culturally structured environments (pp. 105-135). Norwood, NJ.: Ablex Publishing Corporation.

Sloper, P., Knussen, C., Turner, S. \& Cunningham, C. (1991). Factors related to stress and satisfaction with life in families of children with Down's syndrome. Journal of Child Psychology and Psychiatry, 32, 655-676.

Taveira, R.M.T. (1995). Privação auditiva precoce em crianças portadoras da síndrome de Down e suas implicações para o desenvolvimento da linguagem. Dissertação de Mestrado, Universidade de Brasília, Brasília.

Turnbull, A.P. \& Ruef, M. (1996). Family perspectives on problem behavior. Mental Retardation, 34, 280-293.

Vygotsky, L. (1994). The problem of the environment. Em R. Van der Deer \& J. Valsiner (Orgs.), The Vygotsky Reader (pp. 338354). Oxford, UK: Basil Blackwell.

Zamberlan, M.A.T. \& Biasoli-Alves, Z.M.M. (1996). Interações familiares: teoria, pesquisa e subsídios à intervenção. Londrina: Editora da UEL. 